\title{
Evaluation of Role of Tru-Cut Biopsy in the Diagnosis of Clinically Palpable Breast Lumps
}

\author{
Manoj Krishna C. ${ }^{1}$, Narendra M. C. ${ }^{2}$, Mutheeswaraiah Y. ${ }^{3}$, Venkata Prakash G. ${ }^{4}$, \\ Nagamuneiah S..$^{5}$, Srihari Rao B. ${ }^{6}$, Sravya S. ${ }^{7}$
}

${ }^{1}$ Department of General Surgery, SVIMS-SPMC (W), Tirupati, Andhra Pradesh, India. ${ }^{2}$ Department of General Surgery, SVIMS-SPMC (W), Tirupati, Andhra Pradesh, India. ${ }^{3}$ Department of General Surgery, SVIMS-SPMC (W), Tirupati, Andhra Pradesh, India. ${ }^{4}$ Department of General Surgery, SVRRGGH, Tirupati, Andhra Pradesh, India. ${ }^{5}$ Department of General Surgery, SVRRGGH, Tirupati, Andhra Pradesh, India. ${ }^{6}$ Department of General Surgery, SVIMS-SPMC (W), Tirupati, Andhra Pradesh, India. ${ }^{7}$ Department of General Surgery, SVIMS-SPMC (W), Tirupati, Andhra Pradesh, India.

\section{ABSTRACT}

\section{BACKGROUND}

Many diseases affect the breast that range from inflammatory conditions, benign lesions to malignant lesions, most of which present as lumps in the breast. Breast lumps are one of the frequent complaints that we come across in surgical OPDs. Breast lumps not only create apprehension but also can cause unacceptable pain and impairment if they are found to be malignant. Fine Needle Aspiration Cytology (FNAC), Tru-Cut biopsy, incision biopsy and excision biopsy are the pathological investigations available for the diagnosis of breast lesions. This study is done to evaluate the role of Tru-Cut biopsy in diagnosing the breast lesions and compare it with FNAC and histopathology.

\section{METHODS}

This prospective study is conducted in the Department of General Surgery at a tertiary care centre from September 2015 to November 2016 among patients attending surgical OPD and admitted in general surgical wards with clinically palpable breast lumps.

\section{RESULTS}

The sensitivity, specificity, PPV, NPV and diagnostic accuracy of FNAC were $86.36 \%$, $93.75 \%, 90.47 \%, 90.90 \%$ and $90.74 \%$ respectively. For Tru-Cut biopsy the values were $95.45 \%, 100 \%, 100 \%, 96.96 \%$ and $98.14 \%$ respectively.

\section{CONCLUSIONS}

Tru-Cut biopsy has better efficacy over FNAC in our study. The superiority of TruCut biopsy is particularly seen in Sclerosing, papillary, fibro-epithelial lesions and malignancies with inconclusive and suspicious FNAC results.

\section{KEY WORDS}

Breast Lumps, Benign, Malignant, FNAC, Tru-Cut Biopsy, Oestrogen Receptor, Progesterone Receptor, Sclerosing Lesions, Papillary Lesions, Fibroepithelial Lesions
Corresponding Author:

Dr. Narendra M. C.,

Assistant Professor,

Department of General Surgery,

SVIMS-SPMC (W), Tirupati,

Andhra Pradesh, India.

E-mail:drnarendramc@gmail.com

DOI: $10.14260 /$ jemds/2020/278

Financial or Other Competing Interests: None.

How to Cite This Article:

Krishna MC, Narendra MC, Mutheeswaraiah $Y$, et al. Evaluation of role of Tru-Cut biopsy in diagnosis of clinically palpable breast lumps. J. Evolution Med. Dent. Sci. 2020;9(15):1281-1285, DOI: $10.14260 /$ jemds/2020/278

Submission 12-02-2020,

Peer Review 25-03-2020

Acceptance 31-03-2020,

Published 13-04-2020.

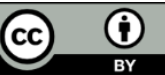




\section{BACKGROUND}

Many diseases affect the breast that range from inflammatory conditions, benign to malignant, most of which present as lumps in the breast. Breast lumps are one of the frequent complaints that we come across in surgical OPDs. Breast lumps not only creates apprehension but also can cause unacceptable pain and impairment if they are found to be malignant. The most important step is the preoperative decision making to differentiate between benign and malignant lesions which helps in planning the treatment.(1) Patients presenting with breast lumps should be subjected to Triple Assessment which includes Clinical Examination, Radiological imaging and pathological analysis. The positive predictive value (PPV) of this combination should exceed 99.9\%. Various pathologic diagnostic tools have been developed to identify a sensitive, specific, efficient and economical approach to differentiate benign and malignant lesions. Fine Needle Aspiration Cytology, Tru-Cut biopsy, Incision biopsy, Excision biopsy are the pathological investigations available for diagnosis of breast lesions.

FNAC is the most commonly used diagnostic tool for cytological analysis. It is least invasive, rapid and accurate if both operator and cytologist are experienced. However, false negatives do occur, mainly through sampling error, and invasive cancer cannot be distinguished from in situ disease. Tru-Cut biopsy is a good tool not only for diagnosis but also for histological typing, grading and ER/PR /HERCEPTIN receptors. The usage of Tru-Cut biopsy in diagnosis of breast lumps has been gradually increasing. However, there is some uncertainty in determining the best initial diagnostic modality between FNAC and Tru-Cut biopsy for diagnosis of benign as well as malignant lesions. This study is done to evaluate the role of Tru-Cut biopsy and it's efficacy in diagnosing the breast lesions and to compare it with FNAC and histopathology.

\section{METHODS}

\section{Source of Data}

This cross-sectional study is conducted in Department of General Surgery, SVRRGGH, after obtaining clearance from the Institutional Ethics Committee of S.V. Medical College, Tirupati, from September 2015 to November 2016 on patients attending surgical OPD and admitted in General Surgical wards with clinically palpable breast lumps. Informed consent is taken from the patients for physical examination and investigations giving due respect to maintain patients privacy and keep her comfortable. 54 patients have been included in the study.

\section{Inclusion Criteria}

All female patients above the age of 20 years with a clinically palpable breast lump.

\section{Exclusion Criteria}

1. Patients who are non-compliant for Tru-Cut biopsy.

2. Patients who are not willing to give consent.

\section{Procedure}

A detailed history is taken, clinical examination, radiological imaging, FNAC, and Tru-Cut biopsy are done in these patients. ${ }^{(2)}$

\section{Procedure for Tru-Cut Biopsy}

- The skin overlying the lump is infiltrated with one $\mathrm{ml}$ of $2 \%$ lignocaine.

- A small incision of size approx. $5 \mathrm{~mm}$ is given on skin after fixing the lump between thumb and index finger of the left hand.

- Tru-Cut biopsy needle is introduced through the incision and obturator thrust into the lump.

- The Sheath is advanced over the obturator, trapping tissue in the specimen notch.

- The entire needle is then removed and the biopsy material is placed in $10 \%$ formalin.

- Pressure is applied over the wound site to control haemorrhage.

- The procedure is repeated in four different directions until four biopsy pieces are obtained.

\section{Statistical Analysis}

Statistical data is analysed and the data is expressed as mean for metric variables, and as frequency (percentage) for categorical variables. Sensitivity, specificity, Positive Predictive Value, Negative Predictive Value and Diagnostic accuracy are calculated. To compare two interventions, Student's t-test is used for metric variables and the Chisquare test for categorical variables. The statistical significance value is set at $\mathrm{p}<0.05$.

\section{RESULTS}

\begin{tabular}{|cccc|}
\hline $\begin{array}{c}\text { Nature of } \\
\text { Lesion }\end{array}$ & $\begin{array}{c}\text { FNAC } \\
\text { Benign }\end{array}$ & $\begin{array}{c}\text { Tru-Cut Biopsy } \\
\text { (\%) }\end{array}$ & $\begin{array}{c}\text { Histopathology } \\
\text { (\%) }\end{array}$ \\
Malignant & $16(29.52)$ & $33(61.11)$ & $32(59.26)$ \\
Inconclusive & $1(1.85)$ & $21(38.89)$ & $22(40.74)$ \\
\hline \multicolumn{2}{r}{ Table 1. Distribution of Benign and Malignant Lesions } \\
on FNAC, Tru-Cut Biopsy and Histopathology \\
\hline
\end{tabular}

\begin{tabular}{|c|c|c|c|}
\hline \multirow{2}{*}{ FNAC } & \multicolumn{2}{|c|}{ Histopathology } & \multirow{2}{*}{ Total } \\
\hline & Malignant (\%) & Benign (\%) & \\
\hline Malignant & 19(35.19) & $2(3.70)$ & $21(38.89)$ \\
\hline Benign & $3(5.56)$ & $30(55.55)$ & $33(61.11)$ \\
\hline Total & $22(40.74)$ & $32(59.26)$ & $54(100)$ \\
\hline \multicolumn{4}{|c|}{ Table 2. Comparison of FNAC with Histopathology } \\
\hline
\end{tabular}

\begin{tabular}{|cccc|}
\hline \multirow{4}{4}{ Histopathology } \\
Tru-Cut biopsy & $\begin{array}{c}\text { Malignant } \\
\text { (\%) }\end{array}$ & Benign & Total \\
Malignant & $21(38.89)$ & $0(0)$ & $21(38.89)$ \\
Benign & $1(1.85)$ & $32(59.26)$ & $33(61.11)$ \\
Total & $\mathbf{2 2 ( 4 0 . 7 4 )}$ & $\mathbf{3 2 ( 5 9 . 2 6 )}$ & $\mathbf{5 4 ( 1 0 0 )}$ \\
\hline Table 3. Comparison of Tru-Cut Biopsy with Histopathology \\
\hline
\end{tabular}

\begin{tabular}{|ccc|}
\hline Parameter & FNAC (\%) & Tru-Cut Biopsy (\%) \\
Sensitivity & 86.36 & 95.45 \\
Specificity & 93.75 & 100 \\
Positive Predictive Value & 90.47 & 100 \\
Negative Predictive Value & 90.90 & 96.96 \\
Diagnostic accuracy & 90.74 & 98.14 \\
\hline \multicolumn{2}{|c|}{ Table 4. Comparison between FNAC And Tru-Cut Biopsy } \\
\hline
\end{tabular}




\begin{tabular}{|c|c|c|c|}
\hline Sl. No. & FNAC & Tru-Cut & Histopathology \\
\hline 1 & Fibroadenoma & Sclerosing adenosis & Sclerosing adenosis \\
\hline 2 & Fibroadenoma & Sclerosing adenosis & Sclerosing adenosis \\
\hline 3 & Fibroadenoma & Sclerosing adenosis & Sclerosing adenosis \\
\hline 4 & $\begin{array}{l}\text { Suspicious of } \\
\text { malignancy }\end{array}$ & Sclerosing adenosis & Sclerosing adenosis \\
\hline 5 & Fibrocystic disease & Phyllodes tumour & Phyllodes tumour \\
\hline 6 & Fibroadenoma & Phyllodes tumour & Phyllodes tumour \\
\hline 7 & Papilloma & $\begin{array}{l}\text { Invasive papillary } \\
\text { carcinoma }\end{array}$ & $\begin{array}{l}\text { Invasive papillary } \\
\text { carcinoma }\end{array}$ \\
\hline 8 & $\begin{array}{l}\text { Suspicious of } \\
\text { malignancy }\end{array}$ & Fibromatosis & Fibromatosis \\
\hline 9 & $\begin{array}{l}\text { Suspicious of } \\
\text { malignancy }\end{array}$ & $\begin{array}{l}\text { Invasive ductal } \\
\text { carcinoma }\end{array}$ & $\begin{array}{l}\text { Invasive ductal } \\
\text { carcinoma }\end{array}$ \\
\hline 10 & $\begin{array}{l}\text { Suspicious of } \\
\text { malignancy }\end{array}$ & $\begin{array}{l}\text { Invasive ductal } \\
\text { carcinoma }\end{array}$ & $\begin{array}{l}\text { Invasive ductal } \\
\text { carcinoma }\end{array}$ \\
\hline 11 & Inconclusive & Invasive ductal carcinoma & Invasive ductal carcinoma \\
\hline \multicolumn{4}{|c|}{ Table 5. Differences between FNAC and Tru-Cut Biopsy } \\
\hline
\end{tabular}
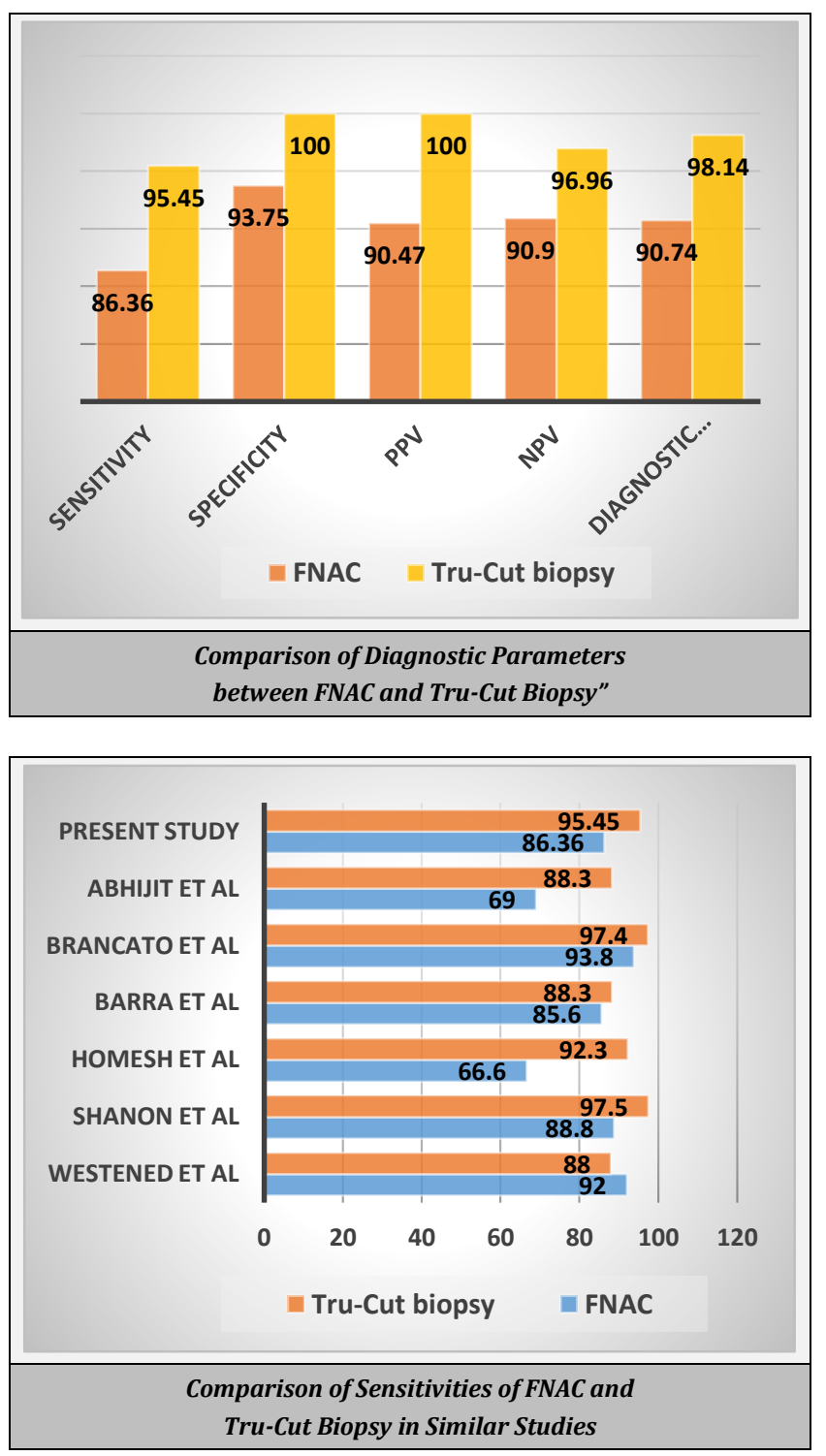

54 patients are included in the study. The patients` aged from 20 to 80 years with a mean age of $41.35 \pm 15.45$ years. Breast lumps are more common in $20-30$ years age group (17 patients) than patients aged more than 60 years (6 patients). The mean age of patients with benign lesions is $33.57 \pm 12.38$ years and with malignant lesions is $52.52 \pm 12.72$ years. The difference between them is statistically significant $(\mathrm{P}<0.0001)$. The right breast is involved in 26 patients, left breast in 27 patients and both breasts involved in 1 patient. The upper outer quadrant is more commonly involved (31 patients) and the Lower inner quadrant is least commonly involved ( 3 patients).

The sensitivity, specificity, PPV and NPV and diagnostic accuracy for FNAC are $86.36 \%, 93.75 \%, 90.47 \%, 90.90 \%$ and $90.74 \%$ respectively. For Tru-Cut biopsy the values are $95.45 \%, 100 \%, 100 \%, 96.96 \%$ and $98.14 \%$ respectively. These parameters are higher for Tru-Cut biopsy indicating higher efficacy.

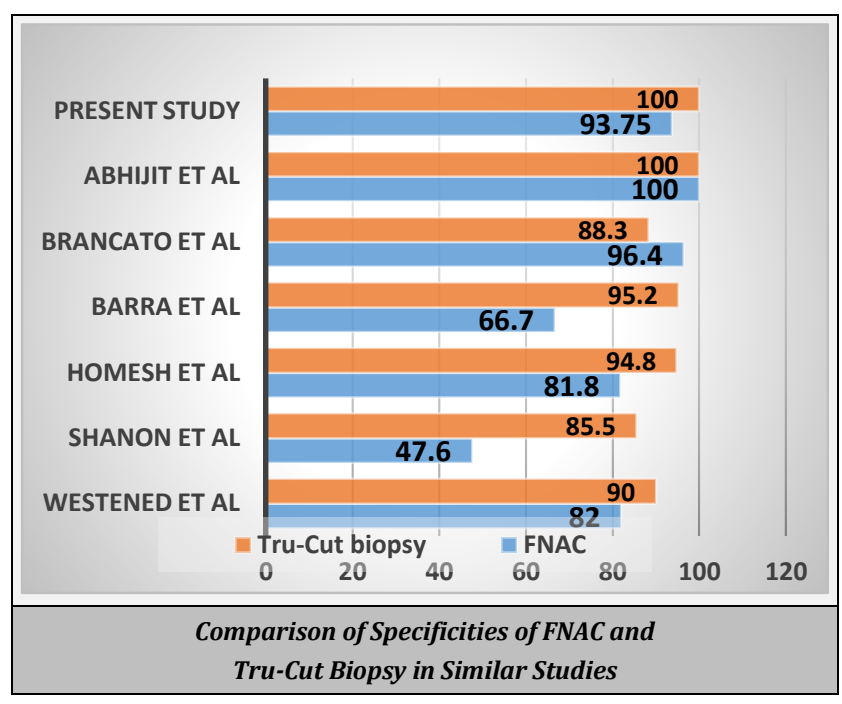

\section{DISCUSSION}

In the present study, 54 patients with age ranging from 20 to 80 years with a mean age of $41.35 \pm 15.45$ years are included. The majority of the patients are in the age group of $20-30$ years $(31.48 \%)$. The incidence of breast lumps decreased with each decade of advancing age after third decade (20-30 years) with the least number of cases reported after 60 years. Most of the breast lumps between 20-40 years are benign. The mean age for benign lumps is $33.57 \pm 12.38$ years.

Out of 22 malignant lesions the incidence is highest between $41-50$ years ( 8 cases, $36.36 \%$ ) followed by $51-60$ age group ( 5 patients, $22.73 \%$ ). The mean age for malignant lumps is $52.52 \pm 12.72$ years. The difference between the mean ages being statistically significant indicating malignant lesions are more common in older age group. Right breast and left breast are equally involved, $48.15 \%$ and $50 \%$ respectively with bilateral involvement in $1.85 \%$.

$57.4 \%$ (31 cases) of lumps are found in the Upper outer quadrant of breast indicating that the Upper outer quadrant is the most common site for breast lumps. $5.55 \%$ (3 cases) of lumps are found in Lower inner quadrant which is the least common site. The majority of lesions are benign (59.26\%). Fibroadenoma is the most common benign lesion (56.25\%) followed by Sclerosing adenosis (12.5\%), Benign phyllodes tumour (12.5\%), Fibrocystic disease (9.38\%), Fibromatosis (3.13\%), Granulomatous mastitis (3.13\%).

Malignant lesions are found in $40.74 \%$ of patients. Invasive ductal carcinoma being the most common malignant lesion (95.45\%). Of the invasive ductal carcinoma, No Other Specified (NOS) type is the most common subtype followed by papillary variant and medullary variant in decreasing order. One case of malignant phyllodes tumour is identified. 
The difference between FNAC and Tru-Cut biopsy in the present study are seen in the following lesions:

\section{Sclerosing Lesions}

Complex sclerosing lesions are considered to be nightmares for pathologists and pose a significant diagnostic problem.(3) The use of Tru-Cut biopsy for diagnosis in these conditions helps to decrease the diagnostic dilemma. In our study four such cases are reported. Three of which have been reported as Fibroadenoma and one reported as a malignancy on FNAC. But, on Tru-Cut biopsy, these cases are found to be sclerosing adenosis which are confirmed even by histopathology (table$5)$.

\section{Fibro-Epithelial Lesions}

Fibro epithelial lesions of the breast encompass commonly occurring fibroadenomas and rare phyllodes tumours. Phyllodes tumour can be potentially malignant and require wide local excision to prevent recurrence. The diagnosis between both these pathologies by FNAC is challenging and is hindered by the lack of universally accepted criteria.(4) Two such cases have been reported in the present study where Phyllodes tumour has been misdiagnosed as fibroadenoma and fibrocystic disease by FNAC which later proved to be Phyllodes tumour on Tru-Cut biopsy and confirmed on histopathology. Accuracy by Tru-Cut biopsy is high (100\%), as demonstrated in our study (table-5).

\section{Papillary Lesions}

Papillary lesions comprise a spectrum from benign ductal papilloma to papillary carcinoma. The overall accuracy of FNAC to differentiate benign from malignant papillary lesions is low. Tru-Cut biopsy helps in distinguishing papilloma from invasive papillary carcinoma. One such case has been observed in this study (table-5).

\section{Suspicious and Inconclusive FNAC Results}

In suspicious and inconclusive FNAC results, Tru-Cut biopsy can differentiate malignant lesions from benign lesions with high accuracy. Three such cases are reported in the present study (table-5). In two cases FNAC is suspicious of malignancy. In one case FNAC is inconclusive. Tru-Cut biopsy diagnosed carcinoma in all the three cases which are confirmed even by histopathology.

\section{Comparison of FNAC and Tru-Cut Biopsy in Diagnosing Malignant Lesions: \\ Out of 22 malignant lesions, FNAC diagnosed 16 cases as malignant where Tru-Cut biopsy diagnosed 21 cases as malignant. In 2 cases FNAC is suspicious of malignancy which are found to be malignant on Tru-Cut biopsy. In 1 case FNAC is inconclusive which on Tru-Cut biopsy proved to be malignant. 3 malignant cases are reported as benign by FNAC, 2 of which are found to be malignant on Tru-Cut biopsy. In 1 case Tru-Cut biopsy is negative for malignancy which was found to be malignant on histopathology (false negative).}

\section{Comparison of Results of Tru-Cut Biopsy with Other Studies}

In the present study the sensitivity, specificity, PPV, NPV, and diagnostic accuracy of Tru-Cut biopsy are found to be 95.45\%, 100\%, 100\%, 96.96\% and 98.14\% respectively and that of FNAC are $86.36 \%, 93.75 \%, 90.47 \%, 90.90 \%$ and 90.74\%. In a study by Barra et al, 2008,(5) the sensitivity, specificity, PPV and NPV of Tru-Cut biopsy are found to be $88.3 \%, 95.2 \%, 100 \%$ and $74.1 \%$ respectively. The results of the present study are similar to this study except for NPV which is less in the study by Barra et al. Homesh et al study(6) showed that the sensitivity, specificity, PPV and NPV of TruCut biopsy to be $92.3 \%, 94.8 \%, 100 \%, 100 \%$ respectively. These results are comparable to the present study. The present study results are also similar to studies by Rikabi et al,(7) Brancato et al(8) and Abhijit Saha et al.(9) No false positives have been reported in the present study. Only one false negative has been reported. This is because of the error in sampling the tissue. This error can be reduced by taking multiple cores of tissue from the lesion. As the number of core pieces increases the number of false negatives decreases. Other methods of decreasing false negatives are Image-guided biopsies,(10,11) Automated biopsy needle(12) and Vacuum Assisted Breast Biopsy(13,14) The concordance rates for Hormone receptor status on Tru-Cut needle biopsy are high and Tru-Cut needle biopsy specimens can be used for hormone receptor status assessment with good accuracy(15,16,17).

\section{Disadvantages of Tru-Cut Biopsy}

Although the cost for a single FNAC is lower than Tru-Cut biopsy, the cost to obtain a reliable diagnosis is less with a Tru-Cut biopsy. Routinely doing FNAC and going for Tru-Cut is more costly compared to Truc-cut biopsy alone. Large studies are required to measure the cost-effectiveness. The time taken for diagnosis in Tru-Cut biopsy is higher compared to FNAC. This can be overcome by Core Biopsy Imprint Cytology (CBIC) and Core Wash cytology (CWC).(18,19,20)

\section{Strengths and Limitations}

The main strength of this study is that FNAC and Tru-Cut biopsy are done in all 54 patients and thereby resulting in a direct comparison of these two modalities in diagnosing benign and malignant lesions of breast.

Non-usage of image guidance is a limitation of this study.

\section{CONCLUSIONS}

Tru-Cut biopsy is superior to FNAC and can be used as an initial diagnostic procedure in diagnosing breast lumps. However, in resource-limited settings where Tru-Cut biopsy cannot be done in all individuals, it can be done by careful selection of patients based on clinical examination and imaging. Tru-Cut Biopsy is particularly helpful when 
1. The lump is suspected to be malignant on clinical examination.

2. FNAC is inconclusive

3. FNAC is suspicious of malignancy

4. FNAC is negative but clinical examination and imaging are in favour of a malignant lesion.

5. Lumps are impalpable.

6. Neo-adjuvant hormonal therapy is required in patients with advanced breast cancer.

\section{REFERENCES}

[1] Williams NS, O'Connel PR, McCaskle AW. The Breast. In: Bailey \& Love`s short practice of surgery. $27^{\text {th }}$ edn. Boca Raton, Florida: CRC Press 2018: p. 860-82.

[2] Kernohan R, Logan H. Tru-Cut needle biopsy in breast lumps. Ulster Med J 1983;52(2):142-4.

[3] Mitra S, Dey P. Fine-needle aspiration and core biopsy in the diagnosis of breast lesions: a comparison and review of the literature. Cytojournal 2016;13(1):18.

[4] Willems SM, Van Deurzen CHM, Van Diest PJ. Diagnosis of breast lesions: fine-needle aspiration cytology or core needle biopsy? A review. J Clin Pathol 2012;65(4):28792.

[5] De Almeida BA, Gobbi H, de L. Rezende CA, et al. A comparison of aspiration cytology and core needle biopsy according to tumor size of suspicious breast lesions. Diagn Cytopathol 2008;36(1):26-31.

[6] Homesh NA, Issa MA, El-Sofiani HA. The diagnostic accuracy of fine needle aspiration cytology versus core needle biopsy for palpable breast lump(s). Saudi Med J 2005;26(1):42-6.

[7] Rikabi A, Hussain S. Diagnostic usefulness of Tru-Cut biopsy in the diagnosis of breast lesions. Oman Med J 2013;28(2):125-7.

[8] Brancato B, Crocetti E, Bianchi S, et al. Accuracy of needle biopsy of breast lesions visible on ultrasound: audit of fine needle versus core needle biopsy in 3233 consecutive samplings with ascertained outcomes. Breast 2012;21(4):449-54.
[9] Saha A, Mukhopadhyay M, Das C, et al. FNAC versus core needle biopsy: a comparative study in evaluation of palpable breast lump. J Clin Diagnostic Res 2016;10(2):EC05-EC08.

[10] Hari S, Kumari S, Srivastava A, et al. Image guided versus palpation guided core needle biopsy of palpable breast masses: a prospective study. Indian J Med Res 2016;143(5):597-604.

[11] Chevrier MC, David J, El Khoury M, et al. Breast biopsies under magnetic resonance imaging guidance: challenges of an essential but imperfect technique. Curr Probl Diagn Radiol 2016;45(3):193-204.

[12] Sridharan R, Yunos SM, Aziz S, et al. Comparison on the use of semi-automated and automated core biopsy needle in ultrasound guided breast biopsy. Med J Malaysia 2015;70(6):326-33.

[13] Amadori R, Fontana A, Sartani A, et al. Vacuum-assisted breast biopsy (VABB) for the diagnosis of nonpalpable breast lesions: results of 600 procedures. Eur J Surg Oncol 2010;36(10):P1018.

[14] Park HL, Hong J. Vacuum-assisted breast biopsy for breast cancer. Gland Surg 2014;3(2):120-7.

[15] Dekker TJA, Smit VTHBM, Hooijer GKJ, et al. Reliability of core needle biopsy for determining ER and HER2 status in breast cancer. Ann Oncol 2013;24(4):931-7.

[16] Middleton LP. Preoperative profiling of symptomatic breast cancer by diagnostic core biopsy. Breast Dis 2007;18(1):66.

[17] Usami S, Moriya T, Amari M, et al. Reliability of prognostic factors in breast carcinoma determined by core needle biopsy. Jpn J Clin Oncol 2007;37(4):250-5.

[18] Kulkarni D, Irvine T, Reyes RJ. The use of core biopsy imprint cytology in the "one-stop" breast clinic. Eur J Surg Oncol 2009;35(10):1037-40.

[19] Schulz-Wendtland R, Fasching PA, Bani MR, et al. Touch imprint cytology and stereotactically - guided core needle biopsy of suspicious breast lesions: 15-year follow-up. Geburtshilfe Frauenheilkd 2016;76(1):59-64.

[20] Wauters CAP, Sanders-Eras MC, De Kievit-Van der Heijden IM, et al. Modified core wash cytology (CWC), an asset in the diagnostic work-up of breast lesions. Eur J Surg Oncol 2010;36(10):957-62. 